\title{
ACCION REPUBLICANA Y LA ESTABILIDAD GUBERNAMENTAL EN EL SISTEMA DE PARTIDOS DE LA II REPUBLICA
}

por EDUARDO ESPIN Universidad Complutense

La intención del presente artículo es contribuir al conocimiento del sistema de partidos de la segunda República española, profundizando así en el análisis de lós sistemas pluripartidistas. Aunque recientemente van apareciendo trabajos valiosos sobre este aspecto del período republicano (1), queda todavía mucho por estudiar, como lo demuestra el que varios partidos de la época carezcan todavía de una investigación profunda. Y, huelga decirlo, sólo con un conocimiento suficiente de los «elementos» de un sistema de partidos puede abordarse de manera definitiva el análisis del propio sistema (2).

Nuestra perspectiva va a ser una aproximación al sistema de partidos a partir de la función desarrollada en él por un partido pequeño, Acción Republicana, que a pesar de sus dimensiones presentaba unos rasgos que le confieren el suficiente interés como para analizar detenidamente su actuación. El interés va además más allá de constatar cuál fue el papel de

(1) El que más específicamente aborda el tema es el de S. Varela, Partidos y Parlamento en la II República española, Ariel, Barcelona, 1978.

(2) Este artículo se basa precisamente en un capítulo de mi tesis doctoral «El partido de Acción Republicana, 1925-1934", leída en la Facultad de Derecho de la Universidad Complutense, actualmente en trámite de publicación. En este sentido hay que advertir que algunas afirmaciones contenidas en este artículo encuentran su apoyadura documental en el desarrollo de la investigación sobre Acción Republicana, sin que aquí se cite, para evitar un excesivo aparato de notas. 
Acción Republicana. En efecto, hay un hecho en el funcionamiento del sistema político republicano al que usualmente no se le ha prestado la suficiente atención, y es la estabilidad gubernamental durante el bienio reformista.

La República pasa por ser in toto un período de fuerte inestabilidad gubernamental, lo que es, como luego veremos, por lo menos inexacto. Pues bien, nuestra intención es asimismo ver cuáles fueron las causas de tal estabilidad perceptible en ese bienio y comprobar hasta qué punto puede atribuirse a Acción Republicana, partido del presidente Azaña, quien fue jefe de Gobierno ininterrumpidamente desde octubre de 1931 a septiembre de 1933, o si más bien dicha estabilidad tuvo causas ajenas al sistema de partidos propiamente dicho.

Acción Republicana había sido fundada en 1925, aunque hasta 1930 , caído ya Primo de Rivera, no actuó públicamente. En los meses anteriores y posteriores a la proclamación de la República experimentó un crecimiento notable - como la mayoría de los partidos republicanos-, aunque de todas formas menor al del Radical Socialista (PRRS), que aspiraba a ocupar en principio el mismo espacio político, la izquierda del republicanismo. $Y$ a pesar de que su crecimiento se mantuvo ininterrumpido hasta 1933, nunca dejó de ser un partido de reducidas dimensiones. Acción Republicana dejó de existir en cuánto tal a comienzos de 1934, cuando se fusionó con la Orga y con un sector de los Radical Socialistas, dando lugar a Izquierda Republicana.

Azaña, fundador; presidente y líder indiscutido del partido, fue su principal capital político y el responsable tanto de sus éxitos como de sus fracasos. Sin embargo, no cabe deducir de ello, como es frecuente en la bibliografía, que Acción Republicana fuera un mero grupo de intelectuales partidarios de Azaña, sin ninguna entidad como partido (3). Funcionó como tal, tuvo una organización que alcanzó un arraigo a veces importante en algunas provincias y un funcionamiento partidista no inferior al de otros partidos republicanos de mayor importancia. Todo esto, sobre lo que no podemos extendernos aquí, justifica a nuestro juicio el objetivo de analizar el papel de Acción Republicana en el sistema de partidos y su posible contribución a la estabilidad de los gobiernos Azaña.

(3) El caso más típico es Tuñón de Lara, quien sistemáticamente trata a Acción Republicana como un grupo de amigos de Azaña. Vid. La II República española, vol. 1, págs. 15 y 25. Siglo XXI, Madrid. 1976. 


\section{EL SISTEMA DE PARTIDOS REPUBLICANO}

Por sistema de partidos se entiende las relaciones existentes entre el conjunto de partidos de un sistema político (4). Se habla de sistema en la medida en que se hace referencia a relaciones estables, que se mantienen. mientras los partidos sujetos de estas relaciones no experimenten transformaciones de importancia. No hay que olvidar, además, que un sistema de partidos, si está consolidado tiende a favorecer, como toda estructura estable, la congelación de la fuerza relativa de los partidos que lo componen, esto es, en última instancia, su propia permanencia.

A la hora de abordar el sistema de partidos de la II República desde la perspectiva de Acción Republicana, tenemos dos límites, uno espacial y otro cronológico. El primero en la medida en que tan sólo pretendemos analizar un aspecto sectorial del sistema de partidos republicano, el papel de uno de los numerosos sujetos del mismo en su relación con el todo. Cronológico en cuanto que sólo estudiaremos el período inicial de formación, el bienio 1931-1933, período en el que se perfilaron los rasgos del nuevo sistema - que no llegó a consolidarse a consecuencia de la violenta ruptura del sistema político en julio del 36- y además en el cual se dio un factor del sistema político que faltaría ya hasta 1936, la estabilidad gubernamental; factor como se podrá comprender íntimamente ligado al sistema de partidos imperante.

Es evidente, sin embargo, que antes de centrarnos en el objeto específico de este artículo, deberemos apuntar algunas líneas generales del sistema de partidos en su conjunto. Desde luego porque sólo así quedará clara la posición de Acción Republicana en el sistema, pero también y fundamentalmente porque apuntar cuál fue esa posición exige tener formada previamente una idea clara de la estructura básica del sistema en su totalidad (5).

Vamos, por tanto, a dar un breve repaso al sistema de partidos, comenzando por aludir al polémico tema de la influencia ejercitada sobre él por el régimen electoral.

Es tradicional, desde que Duverger formulara sus conocidas tesis sobre la influencia de los sitemas electorales en los sitemas de partidos, la

(4) Vid. por ejemplo Duverger, Los partidos políticos, pág. 231, FCE, México, 1972.

(5) Con las reservas antes aludidas respecto a la posibilidad de analizar un sistema de partidos sin que exista un conocimiento profundo previo de sus partidos integrantes, metodológicamente es necesario contar con un modelo provisional del funcionamiento del conjunto del sistema para cualquier aproximación al mismo. 
polémica sobre el grado y límites de esa influencia, cuando no sobre su misma existencia.

No es nuestra intención proceder ahora a un análisis sobre si esta influencia se dio y en qué medida, en el caso que nos ocupa de la II República. Nos vamos a basar en la generalizada opinión de todos los autores que han tratado el tema de que, en efecto, la influencia del sistema electoral republicano sobre el sistema de partidos no sólo existió sino que fue considerable (6).

En efecto el punto de acuerdo al que han llegado los estudiosos del tema es que el sistema de lista en circunscripciones plurinominales combinado con un escrutinio mayoritario con reserva de puestos a las minorías, tal como se utilizó en la República, favoreció la formación de alianzas lo más amplias posibles, con objeto de beneficiarse de la enorme prima a la mayoría que otorgaba el sistema (un 80 por 100 de los puestos aproximadamente). El efecto no se percibió en su totalidad hasta las elecciones de 1936, en las que el espectro de partidos se presentó agrupado en torno a dos polos derechista e izquierdista; no sólo los partidos habían aprendido con la experiencia de las dos elecciones anteriores formando dichas coaliciones, sino también los electores, quienes apenas otorgaron votos a las opciones centristas, que se presentaban débiles o desprestigiadas, como el Partido Radical.

Aí, pues, si el sistema de partidos surgido ex novo en 1931 y gestado en los cinco años que van de 1931 a 1936 se caracterizó por esta polarización en dos amplios bloques de alianzas, con un fraccionamiento interno grande (aunque en proceso de concentración), se debió en parte no despreciable a la citada influencia del sistema electoral escogido.

Dos bloques de alianzas sería la máxima simplificación que podríamos hacer del sistema de partidos republicano. Acercándonos algo más a la realidad de tales bloques veríamos que en modo alguno eran homogéneos y unidimensionales. En el interior de cada uno de ellos veríamos en primer lugar una división en un número considerable de partidos. En segundo lugar, la pluridimensionalidad de las alineaciones de todos los partidos integrantes de cada bloque según el problema político que abordásemos (7).

(6) Vid. entre otros Linz. El sistema de partidos en España, págs. 113 y ss. Ed. Narcea. Madrid, 1974.

(7) Sobre la multidimensionalidad de los sistemas de partidos, vid. Sartori, «European Political Parties: The case of Polarized Pluralism», en La Palombara-Weiner, Political Parties and Political Development, Princeton U. Press, 1972, pág. 137; respecto a su aplicación concreta al caso español, Varela, El problema regional en la II República española. Unión Ed., Madrid, 1976. págs. 73 y ss. y especialmente Partidos y Parlamento en la II República. 
No vamos a insistir en la conocida abundancia de partidos durante la República. Basta con observar la relación de partidos presentes en las tres legislaturas republicanas para comprobar un pluripartidismo exacerbado, a lo que habría que sumar los partidos menores sin representación parlamentaria.

Respecto al segundo aspecto nos referimos a un factor puesto de relieve por Varela respecto a nuestra II República, consistente en que las posiciones de los partidos integrantes de cada bloque no coincidían en las principales cuestiones con que se enfrentaron: cuestión regional, problema religioso, reforma agraria, etc. En cada uno de estos temas los partidarios y adversarios de cada solución concreta variaban, con lo que era siempre un delicado equilibrio el que unía a los partidarios integrantes de estos bloques.

El nexo que los mantenía unidos, aparte las consideraciones ideológicas de orden general, era el interés que cada integrante de la coalición mantenía por conseguir el aspecto del programa común que realmente le interesaba. Esto lo vio bien Azaña al simultanear la discusión del Estatuto catalán y la Reforma Agraria para salvar las reticencias de los socialistas hacia el primero y de los catalanes hacia la segunda. Esta pluridimensionalidad, factor de complicación extrema de un sistema de partidos, explica también cómo, por ejemplo, ia minoría vasca ideológicamente conservadora, acabó separándose del bloque derechista al no obtener de éste la autonomía que reivindicaba.

Por último, la inexistencia de un único sistema de partido nacional o, mejor dicho, su coexistencia con subsistemas regionales, principalmente en Cataluña, terminaba por complicar este sistema de partidos, que de forma simplificada hemos descrito (8).

Un rasgo común tenían ambos bloques de partidos, y era la existencia en cada uno de ellos de un partido de masas con un apoyo popular grande: los socialistas en el bloque izquierdista y la Ceda en el bloque conservador. Los primeros eran al comienzo de la República el partido más estructurado de todos, pues salían del período dictatorial con una organización incólume y, para lo habitual en España, relativamente desarrollada y a partir de la proclamación de la República experimentó, como es conocido, un crecimiento acelerado que ya no se detendría.

La Ceda sería el gran partido de masas de la derecha española. Su gran

(8) Sistema de partidos que además contaba con el inconveniente de la debilidad inherente a su constitución ex novo a partir de 1931, vid. Linz, El sistema de partidos..., pág. 109. 
virtud fue la rapidísima constitución a partir de la nada — pues en abril del 31 las derechas quedan completamente desorganizadas- que le permitió ganar unas elecciones dos años después de aparecer; es claro que consideramos, como es habitual, a la Ceda como una etapa más del partido que en un primer momento se llamó Acción Nacional.

La oscilación a la derecha del Partido Radical, junto con los resultados electorales de 1933, hicieron coincidir en una misma coalición, al comienzo meramente parlamentarios y luego gubernamental, a este partido con el de Gil Robles. Sin embargo, mientras el primero era un partido en decadencia, la Ceda era cada vez más y a pesar de su heterogeneidad y ambigüedad políticas el partido que contaba con el apoyo masivo de la derecha económica, de la derecha clerical y de amplias capas medias, formado alrededor de un líder y en defensa de intereses comunes.

Lo que nos interesa destacar especialmente es cómo su líder Gil Robles, gracias a su enorme capacidad organizativa, logró dotar a la derecha de una organización política potente a lo largo del primer bienenio.

Si el apoyo de masas procedía básicamente de la Ceda (y conforme se acerca 1936 cada vez más), el eje político de las colaliciones radical cedistas se situaba inicialmente en el Partido Radical, por diversas razones en las que ahora no podemos entrar. Luego progresivamente el centro político de esta alianza conservadora se desplazó más hacia la derecha, hasta que ante las elecciones de 1936 el Partido Radical quedó desligado del frente derechista y con ello de toda posibilidad de victoria ante la inviabilidad de una alternativa centrista (9).

\section{El frente izquierdista}

Por el lado izquierdista eran los socialistas el partido que proporcionaban el principal apoyo de masas, con la ventaja desde un punto de vista gubernamental que el electorado socialista era una gran parte de la clase trabajadora española, lo que permitía en caso de estar los socialistas en el Gobierno una mayor capacidad de maniobra cara a las reivindicaciones sociales.

Si la alianza radical cedista era un matrimonio de conveniencia surgido en 1933 de forma no prevista de antemano, que se deshizo cuando el partido radical se derrumbó, sin excesivo daño para el bloque derechista (a pesar de la derrota en febrero del 36 , el apoyo electoral al frente derechista

(9) Centrista en consideración al espectro político, tal como se presentaba ante las elecciones, porque social e ideológicamente, la opción radical era en 1936 y para aquella época claramente conservadora. 
fue grande, obteniendo pese al sistema electoral una importante minoría parlamentaria), la unión de republicanos y socialistas tenía una larga tradición detrás que se remontaba a la época monárquica anterior a Primo de Rivera, y que se fortaleció en la etapa final de la lucha contra la Dictadura.

Lo más extraordinario es que, a pesar de ello, la evolución de las relaciones internas de republicanos y socialistas experimentase en el breve período republicano hasta 1936 unos altibajos espectaculares. El más destacado, la ruptura en 1933 de una alianza que razones de tipo político, apoyadas en dicha tradición y en una reciente colaboración gubernamental, hacían ver como imprescindible.

El hecho es que tras esta colaboración gubernamental republicano-socialista, que significaba el punto más estrecho de colaboración entre ambos sectores en toda su historia, en las elecciones de 1933 se rompe el bloque, originando así su derrota estrepitosa -en actas, no en votos-. Lentamente a lo largo de los dos años siguientes, especialmente de 1935, se van reanudando los lazos que aunque no llegan a ser como en 1931-33 _principalmente por las disensiones internas socialistas-, alcanzan a adoptar la alianza electoral del Frente Popular y mal que bien a apoyar un programa de gobierno.

Dentro del bloque izquierdista la otra parte la constituían los partidos republicanos. El principal problema del sector republicano era la división de sus filas. Considerando que sólo a partir de la crisis de diciembre de 1931 comienzan a perfilarse los rasgos de lo que iba a ser el sistema de partidos republicano con la separación del Gobierno de los radicales (a quienes en octubre había precedido la Derecha Liberal Republicana de Maura), el sector republicano de izquierdas que mantuvo la alianza con los socialistas se componía de cuatro partidos fundamentalmente, dos de ámbito nacional, el Radical Socalista y Acción Republicana, y dos regionales, Orga y Esquerra Catalana. Se podría mencionar también al pequeño grupo de los federales, que aunque hasta junio del 33 se mantuvo en una posición ambigua, siguiendo la línea que marcaba el Partido Radical, en esa fecha se incorporó al Gobierno, aunque su reducida fuerza (contaba con 11 diputados) le quita toda relevancia.

Esta división en cuatro, con el agravante de que dos de ellos eran partidos específicamente regionales, puede dar idea de la dificultad que podía conllevar la adopción de decisiones en el seno del Gobierno, de forma que se lograra el consenso de una mayoria tan heterogénea (10).

(10) Sobre el proceso de adopción de decisiones, vid. las dos obras citadas de Varela, especialmente, Partidos y Parlamento... págs. 123 y sigs. 
Los partidos republicanos sufrieron a lo largo de la República un proceso de concentración que habla a favor de una hipotética consolidación del sistema de partidos con grandes opciones políticas, de no mediar la ruptura de 1936. Sin aventurarnos en tales hipótesis, lo que sí cabe constatar es que esos cuatro partidos habían quedado reducidos en 1936, a dos, cuyas relaciones mutuas se habían estrechado. En efecto, radical socialistas, Acción Republicana y Orga se habían fusionado en Izquierda Republicana y aparecían como un partido potente con apoyo de masas; la Esquerra seguía siendo el partido hegemónico en Cataluña.

El sector radical socialista que seguía a Grodón Ordás, fusionado con los radicales de Martínez Barrio en Unión Republicana, puede considerarse que venía a sustituir al Partido Radical en su primitiva posición de 1931 de centro izquierda.

Así, pues, no se puede acusar a los partidos republicanos izquierdistas de ceguera y de falta de realismo, ya que supieron comprender la imperiosa necesidad de reducir las opciones partidistas republicanas. El gran fallo fue el ritmo lento que llevó dicho proceso de unión. Si hemos visto cómo Gil Robles logró tener dispuesto para noviembre de 1933 una maquinaria electoral y partidista capaz de ganar las elecciones, no fue así por parte de los republicanos. En ese momento y a pesar de que la opinión pública republicana había reivindicado a lo largo de 1933 la necesidad de la unión, la izquierda del republicanismo se encontraba más dividida que nunca.

Y aunque la unión fundamental - Izquierda Republicana- se consiguió tan sólo meses después, ya era demasiado tarde; se veían ya forzados a esperar el desgaste de una legislatura derechista cuya principal labor fue deshacer las reformas del primer bienio. Conviene recordar aquí que aunque sin duda alguna los republicanos de izquierda hubieran conseguido más votos en 1933 de haberse presentado ya unidos en un solo partido (por el simple hecho de la atracción que ejerce un partido grande, más rentable electoralmente que una coalición de pequeños partidos), no fue ésta la causa directa de la victoria derechista, sino la política electoral socialista.

Una vez disueltas las Constituyentes ya no era posible, por falta material de tiempo, una fusión de los republicanos antes de las elecciones (aparte otros factores subjetivos) y, sin embargo, sí lo era, y aparecía como la lógica conclusión de dos años de coalición gubernamental una alianza electoral republicano-socialista, que hubiese cambiado sustancialmente los resultados. No fue posible alcanzarla.

Dado que Izquierda Republicana se constituye en torno al eje de 
Acción Republicana más como una etapa del lento crecimiento de ésta que como una fusión entre partidos iguales, puede considerarse como un fracaso de la dirección de Acción Republicana y en concreoto de su líder Azaña el no haber conseguido la unión con anterioridad, con todo lo que eso comporta.

Desde luego, la falta de interés que mostró Azaña por el aspecto organizativo es un factor a considerar a la hora de comprender la lentitud del proceso de crecimiento del partido y de fusión con las restantes organizaciones republicanas. El era la única personalidad política con la suficiente autoridad como para haber intentado forzar una unión antes de cuando se produjo; de hecho, tras la derrota electoral del 33 sí que puso en juego toda su autoridad en conseguirla. No hay que olvidar que algún intento hizo con anterioridad, como el discurso de Santander en el otoño de 1932. Pero, sin embargo, se despreocupó por completo de la labor material de llevarlo a la práctica, perdiéndose aquella iniciativa en rencillas personalistas; el resultado fue una federación parlamentaria (la FIRPE), que nació muerta, según sus propias palabras.

Por otra parte, si cabe calificar de lenta y tardía la unión de los republicanos de izquierda es tan sólo en el contexto de la época, esto es, por el hecho de que se produjo tras unas elecciones - anticipadas- y sobre todo al compararlo con la labor ya aludida de la derecha, que pudo crear la Ceda en tan corto espacio de tiempo. Pues dada la dificultad siempre existente en fundir diversas organizaciones por la tendencia a subsistir de toda estructura organizativa, no se puede considerar demasiado largo en sí el período de 1931-34 que llevó la formación de Izquierda Republicana.

No hay que olvidar que la tarea de Gil Robles consistió en levantar una organización política de la nada, y si bien esto exigía quizá una mayor dedicación, no tropezaba, en cambio, en tan gran medida, con las resistencias de personas e intereses partidistas. Desde este punto de vista, en el campo republicano la proliferación organizativa obstaculizaba la tarea de construir un gran partido sin ofrecer en cambio la ventaja de encuadrar de forma eficaz al electorado republicano.

Todo esto es cierto. Pero queda el hecho fundamental ya suficientemente reseñado. Para las pretensiones políticas de la coalición azañista y para la propia estabilidad republicana fue fatal el que Azaña no lograra con la misma brevedad, bien unir a los diversos partidos republicanos de izquierda, bien consolidar el suyo aisladamente como un potente partido de masas. 


\section{ACCION REPUBLICANA EN EL SISTEMA PARLAMENTARIO DE PARTIDOS DE 1931 A 1933}

En las Cortes Constituyentes el sistema de partidos ofrecía, de acuerdo con las líneas generales que hemos esbozado, el cuadro siguiente. Una primera etapa transitoria que dura hasta diciembre del 31 , en la que se da una especie de gobierno de todos los partidos, con exclusión de la minoritaria derecha católica - la minoría vasconavarra-; salvo ésta, todas las demás minorías apoyaban más o menos explícitamente al Gobierno. Las mayorías podían oscilar según el tema debatido, pero todavía no se había plasmado un sistema de relaciones estable entre las diversas minorías, a pesar de la proclividad cada vez más clara de los radicales a adoptar posiciones conservadoras.

A partir de la crisis de diciembre de 1931 los radicales quedan fuera del Gobierno por propia voluntad (11). Desde entonces - junto con los federales- oscilarán de una oposición moderada que apoyará no escasas veces al Gobierno a una oposición a ultranza y absoluta a partir de enero de 1933, fase en la que intentarán, por medio de la obstrucción parlamentaria, un bloqueo del Gobierno. Los radicales, una vez enfrentados a la coalición gobernante, y la derecha católica constituyen los dos elementos del bloque derechista que será hegemónico en la segunda legislatura, aunque por entonces nadie preveía que la oscilación del Partido Radical fuera a ser tan grande.

Por parte gubernamental, la coalición izquierdista se componía de los socialistas por un lado y los cuatro partidos republicanos antes citados, el Radical Socialista, Acción Republicana, la Orga y la Esquerra catalana. Vamos a ver a continuación cuál fue la función que desempeñó Acción Republicana, partido que osciló entre los 26 y los 34 miembros a lo largo de esta legislatura. Pues, a pesar de su carácter minoritario, desempeñó un papel central en la coalición gubernamental.

Hasta diciembre del 31 Acción Republicana se encontraba políticamente en el centro de la coalición, con el PSOE y los radical-socialistas a su izquierda y la Derecha Liberal Republicana, radicales y federales a su derecha. Esta posición le permitió durante esos meses ser en ocasiones el árbitro, haciendo oscilar la victoria hacia un sector $\mathrm{u}$ otro de las Cortes, en las que, a pesar de apoyar todos los partidos al Gobierno Provisional, se

(11) Sin duda alguna puede afirmarse esto tras un análisis sistemático de la prensa de la época y de las Memorias legadas por los protagonistas, en contra de las afirmaciones (de entonces y de sus escritos posteriores) de uno de ellos: Lerroux. 
ensayaban diversas coaliciones en función de la materia discutida. La falta de unidad interna de Acción Republicana por aquellos meses quizá debilitó su posición, que pudo ser más determinante de haber jugado conscientemente el papel de eje de la coalición.

Esta posición central desapareció con la remodelación ministerial de diciembre, al prescindirse del ala derecha de la coalición. Ahora Acción Republicana, junto con la minoría gallega —en la que la Orga era mayoritaria- representaba el sector más moderado de la coalición gubernamental, frente a la Esquerra y los Radical-socialistas por un lado y al PSOE por otro. Sin embargo, y a pesar de que el gran partido de la coalición era el socialista, el eje político siguió en torno a las posiciones adoptadas por Acción Republicana.

Y si conservó su papel de eje de la coalición fue porque su identificación con todos los aspectos del programa gubernamental -en todas las «dimensiones» del sistema de partido- le permitía, aun no ocupando ideológicamente el centro de la coalición, seguir siendo el "pivot» sobre el que se formaban las mayorías para cada decisión (12).

Si bien finalmente todos los partidos de la coalición gubernamental acababan votando los proyectos legislativos y decisiones del Gobierno, el apoyo era a veces sumamente reticente por parte de algún integrante de la mayoría. Tan sólo en Acción Republicana se encontraba - no hace falta insistir que tras un proceso de homogeneización interno que llevó varios meses- incondicionalmente detrás de las decisiones gubernamentales. Aunque constituyese el ala moderada de la coalición, era el partido que se interesaba por todos los aspectos de la política gubernamental, y que actuaba con una unidad de la que carecía el Radical Socialista, que podía haber desempeñado ese papel de haber sido un partido menos dividido. Sobre el apoyo de Acción Republicana y del partido o partidos que presionasen a favor de alguna medida se lograba inclinar la balanza de los miembros de la coalición más reacios.

La razón que explica el que Acción Republicana fuera el más identificado con el programa de gobierno de la coalición, es que para los socialistas las reformas realizadas no eran sino una pequeña parte de su programa que aceptaban como un inicio de la transformación de la sociedad española que perseguían. Incluso los radical-socialistas eran más ambiciosos y radi-

(12) Vid. Sartori, íbidem y Parties and party systems y López Guerra y Varela, S., Las coaliciones de gobierno en la II República española, ponencia presentada en el Congreso de Ciencia Política de Zaragoza de marzo de 1978, en El control parlamentario del gobierno en las democracias pluralistas, pág. 167, Labor, Barcelona, 1978. 
cales en sus planteamientos, y en algunos temas como el religioso de un anticlericalismo maximalista.

Respecto a los dos partidos regionales, si bien podían identificarse más con el conjunto de reformas planteadas, se veían especialmente ocupados, sobre todo la Esquerra, por la consecución de su propia autonomía. Autonomía que no quedaba resuelta con el Estatuto, sino que exigía posteriormente el traspaso de servicios, elecciones al Parlamento catalán, etcétera. La Orga en cambio, de una autonomismo más tibio, venía a quedar mucho más cerca de Acción Republicana y de su planteamiento nacional de la política. Como veremos a continuación, por este motivo y por el ascendiente de Azaña sobre Casares, la Orga reforzaría la posición de Acción Republicana en las Cortes.

Si bien la adhesión global de Acción Republicana a la política reformista de Azaña es la base sobre la que se sustentaba el primordial papel político del partido, este papel se articulaba asimismo sobre una serie de factores que realzaban considerablemente la importancia que por su propio peso numérico pudiera tener. En realidad estos factores no tienen que ver ya con la posición política de Acción republicana en las diversas «dimensiones» del sistema de partidos (plano religioso, regional, socioeconómico, etcétera). Son, sin embargo, a nuestro juicio, los canales - de carácter ideológico y organizativo- imprescindibles por los que se consolidaba la función de eje o pivot desempeñada por Acción Republicana.

Uno de estos factores decisivos fue el hecho de ser durante todo el bienio el partido del Presidente del Gobierno. Una postura de Acción Republicana podía significar que detrás se encontraba la opinión de Azaña, y por tanto, existía la posibilidad de un apoyo directo por su parte; de ahí la importancia que para los demás partidos adquiría tener en cuenta la posición adoptada por Acción Republicana.

A su vez, el ascendiente político de Azaña sobre sus compañeros de Gobierno e incluso sobre líderes políticos afines que no pertenecían a él, repercutía en realzar la relevancia de la posición política tanto del propio Azaña como de su partido, principal instrumento de éste en los trabajos y discusiones de las Cortes.

Como ha visto Alfonso Bozzo, la relación política y personal que se estableció entre Azaña y Casares Quiroga significó una atracción de la Orga a la órbita política del Presidente del Gobierno. Lo cual implicaba un robustecimiento paralelo de la posición de Acción Republicana por esa vía indirecta. El nombramiento de Casares como ministro de Gobernación, un puesto de gran responsabilidad política, sería el hecho que trasladaría 
definitivamente los intereses del líder gallego al ámbito nacional, proceso cuya conclusión lógica culminaría en 1934 con la integración de la Orga en un partido nacional que incluyera en su programa la defensa de la autonomía. Durante 1932 y 33 frecuentemente se corrieron rumores de la incorporación del partido de Casares a Acción Republicana, lo que es un índice de la identificación política entre ambas organizaciones.

De igual manera, aunque en menor medida, la influencia de Azaña sobre Domingo y Albornoz suponía una revalorización de Acción Republicana frente al PRRS. La incoherencia y heterogenidad de este partido, y la posición mucho menos firme de sus dos principales líderes en el interior del partido que la que podían tener Casares o Azaña, debilitaba esta influencia. También el mayor radicalismo de sus diputados - por lo menos hasta 1933 - les hacía ser menos sensibles a las posturas adoptadas por Acción Republicana o por Azaña.

Pero con todo se puede observar una expectación por parte del PRRS respecto a las decisiones que pudiera adoptar Acción Republicana, ante el temor de quedarse aislados o enfrentados a la decisión del Presidente del Gobierno, que en último término se verían forzados a aceptar.

Lo mismo puede afirmarse respecto de todos los demás partidos de la coalición, e incluso de los partidos republicanos de oposición, radicales y federales. Nos referimos a la circunstancia general de considerar la posición de Acción Republicana ante cualquier tema como de especial relevancia, no ya porque fuera a ejercer influencia sobre las decisiones a adoptar de todos los demás partidos, sino por indicar probablemente la opinión de Azaña.

Esta relevancia de Acción Republicana se veía reforzada además por una serie de características del partido que en el panorama de partidos republicanos no era frecuente. Nos referimos, por ejemplo, a la disciplina que el partido llegó a adquirir, pasados los primeros meses de actuación parlamentaria. Salvo el Partido Socialista, ninguno de los partidos nacionales, el radical y el radical socialista, consiguieron el mismo grado de unidad, si bien hay que considerar que su mayor tamaño lo hacía más difícil. Tampoco se puede afirmar que la disciplina de Acción Republicana fuese absoluta, o que alcanzase los niveles habituales hoy día, pero en el contexto de las Cortes Constituyentes se le puede calificar de una minoría disciplinada (13).

Ya al final de la legislatura, en el verano de 1933, fue cuando esta

(13) Vid. a este respecto el capítulo VII de mi tesis doctoral «El partido de Acción Republicana, 1925-1934». 
disciplina comenzó a flaquear, no por fraccionamientos a la hora de votar, sino por inasistencia a las sesiones, debido al desaliento de la mayoría parlamentaria ante las dificultades con que se encontraban. Inasistencia que ocasionaría fuertes críticas en la base del partido.

Otro factor que coadyuvaba a destacar la importancia de Acción Republicana era la mayor cohesión ideológica existente en su interior. La autoridad de Azaña contribuyó enormemente a conseguir esta homogeneidad, inexistente en los primeros meses; el hecho cierto es que, aunque en Acción Republicana siguieran existiendo perceptiblemente diputados más progresistas y diputados más conservadores, nunca se manifestó esta polaridad de una forma abierta, con enfrentamientos o riesgo de escisiones. Esta cohesión es la otra cara de la moneda de la identificación con el programa gubernamental, pues es a través de su función de apoyo a la acción gubernamental y a Azaña como Acción Republicana logró su unidad.

Frente a ello, dentro de la coalición gubernamental destacaba la desunión de los radical-socialistas, con el sector más radical en torno a Albornoz, y el resto, hasta la aparición de una importante ala derecha, más cercano a M. Domingo. Posteriormente el ascenso de Gorgón Ordás originaría en 1933 la aparición de esa ála derecha que, aunque minoritaria en el Parlamento, lograría hacerse con el control del partido, provocando la escisión del PRRS.

El caso de los socialistas es diferente, pues su disciplina era muy superior a la de todos los demás partidos, mientras que las dos minorías regionales poseían este carácter regional que les daba un factor de cohesión superior al ideológico.

Por último, habría que considerar, como un factor no despreciable para comprender la posición de Acción Republicana dentro de la mayoría, el prestigio de sus miembros individuales. La cualificación profesional y la reconocida valía intelectual de muchos de ellos convertía a la minoría de Acción Republicana en un pequeño grupo de élite, que durante gran parte de la legislatura constituyente ostentó numerosos cargos de Gobierno.

Esta fama de grupo con prestigiosos intelectuales servía a Acción Republicana, a pesar de la reticencia con que era contemplado por el Jefe del Estado y por algunas figuras de primer orden (Ortega, Unamuno, etc.), para aumentar la espectación ante algunas intervenciones de sus miembros. Estos factores que hemos enumerado (ser el partido del Presidente del Gobierno, con la consiguiente atracción hacia sus planteamientos políticos de otras minorías, su grado de adhesión al programa gubernamental, el prestigio de sus miembros y el aceptable grado de disciplina parlamentaria 
y cohesión interna) aumentaban sin lugar a dudas la importancia parlamentaria del pequeño partido que era Acción Republicana.

De haber logrado un crecimiento más rápido, a lo largo de la misma legislatura constituyente — para lo que el procedimiento más factible era haber conseguido la fusión con Orga y radical-socialistas- puede pensarse que no se hubiera producido una disolución tan pronta de la Cámara, evitándose muchos conflictos posteriores; pero dicha fusión sólo estuvo madura una vez que el desastre electoral republicano de noviembre de 1933 se hubo producido. Porque el gran inconveniente de Azaña fue no contar con un partido lo suficientemente numeroso como para rentabilizar los logros de una política que, aunque criticada por ambos flancos, era coherente. Un gran partido le hubiese permitido además un mayor rapidez en las tareas parlamentarias, cuya lentitud es uno de los aspectos más justificadamente criticados de la labor gubernamental de Azaña. Como luego veremos, el principal paliativo a este defecto numérico — que desde luego no se veía suficientemente compensado por los factores analizados anteriormente - vino dado por la propia actuación personal de Azaña, no ya como jefe de uno de los partidos de la coalición, sino como estadista y Jefe del Gobierno.

Dentro de la evolución del bloque izquierdista a lo largo del bienio constituyente hay que señalar que en la última etapa, a partir de 1933, progresivamente Acción Republicana fue recuperando una posición centrista dentro de la coalición con la aparición del sector derechista en el PRRS. En efecto, no se produjo una identificación de este sector con Acción Republicana como pudiera pensarse, al estar los radical-socialistas habitualmente a la izquierda de Acción Republicana, sino que la disidencia encabezada por Gordón Ordás pasó a ser la derecha de la coalición. De hecho, a duras penas mantuvieron el apoyo al Gobierno - tan sólo porque en la minoría parlamentaria radical-socialistas eran minoría-. Los temas de discrepancia eran la necesidad, desde el punto de vista de los partidarios de Gordón Ordás, de acabar con la colaboración gubernamental socialista y un mayor conservadurismo socioeconómico.

El conjunto de circunstancias analizadas creemos que permiten afirmar la importancia de Acción Republicana como eslabón que facilitaba la cohesión entre los miembros de la coalición republicano-socialista de Azaña.

En efecto, para los socialistas representaba Acción Republicana, aunque pudiera ser más moderada en sus planteamientos que los radical-socialistas, el único partido republicano honesto y consecuente, dispuesto a 
apoyar la política preconizada por Azaña. Eso y el ascendiente personal de Azaña sobre líderes socialistas como Prieto eran el principal lazo de unión de los socialistas a la coalición.

Respecto a los demás partidos republicanos -incluidos el Radical y el Federal- se comportaban con un innegable seguidismo respecto a Acción Republicana como consecuencia de todos los factores enumerados: la personalidad de Azaña y su influjo, la cohesión de Acción Republicana, el prestigio de sus miembros, etc.

Una consecuencia de esta relevancia del partido de Azaña fue la gran cantidad de cargos que ostentaron sus miembros, aunque fueron sobre todo cargos de rango inferior a ministro (14). De todas formas poco se puede concluir en este punto sin disponer de una estadística del reparto de cargos entre los partidos miembros de la coalición, desde gobernadores civiles a ministros. Contar con ese dato podría ser muy indicativo de la capacidad de maniobra de cada partido de la coalición, a más de ser útil para explicar el proceso de consolidación de los partidos en las provincias, proceso para el que contar con un gobernador civil podía ser decisivo (15).

Conviene hacer finalmente una precisión. Puede parecer que la conclusión de un análisis como el precedente es que Acción Republicana fue el partido republicano más significativo de 1931 a 1933 por el papel político desempeñado. Nada más lejos de la realidad y de lo que hemos pretendido resaltar. El énfasis puesto en afirmar la función cubierta por Acción Republicana no es sino el necesario contrapeso a la tendencia existente hasta hoy en la bibliografía que margina sin la debida fundamentación a los pequeños partidos republicanos, sin distinguir entre un fantasmal partido Federal y una Acción Republicana.

Qué duda cabe que tenían más importancia el Radical o el Radical-socialista, que eran los grandes partidos republicanos del primer bienio. Pero lo que sí se puede deducir de nuestro análisis es que mientras estos partidos desempeñaban un papel muy inferior al que podían haber asumido por culpa de falta de dirección política, de divisiones internas, etc., Acción Republicana por el contrario desempeñó uno superior al que podía esperarse de su fuerza organizativa debido al conjunto de circunstancias vistas.

(14) En los cinco ministerios del primer bienio Acción Republicana sólo contó con tres personas en el Gobierno: el propio Azaña, que a partir del segundo Gobierno provisional acumuló Presidencia y Guerra; Giral, ministro de Marina desde octubre de 1931 a junio de 1933, y Viñuales, ministro de Hacienda de junio a septiembre de 1933.

(15) Aunque está por estudiar la persistencia del caciquismo en la República, se puede afirmar sin temor a equivocarse que, si bien se mitigó considerablemente con las reformas electorales, subsistieron no pocas redes de relaciones políticas personalistas. 
Respecto a la colaboración socialista no hay que pensar que se limịtó a prestar un apoyo de masas que faltaba a los republicanos con una actitud meramente pasiva, sin que políticamente tuviese importancia su colaboración (16). Todo lo contrario. La colaboración socialista era la base que permitía un programa reformista como el que puso en marcha Azaña.

Precisamente ese apoyo de masas era el que permitía al Gobierno tener la fuerza política suficiente como para reformar el statu quo social y político. No ya por supuesto por el hecho de la imprescindible base parlamentaria, sino por el respaldo social que significaba.

$\mathrm{Y}$ este respaldo social implicaba que las formas emprendidas tenían -pese a su moderación- un carácter más decididamente reformista que el que hubieran tenido en manos de una hipotética mayoría republicana de izquierdas. Por mucho que nos puedan parecer desde nuestro actual punto de vista excesivamente moderadas dichas reformas, el poder social de la derecha era tan grande que difícilmente podía haberse intentado otra cosa. Y la colaboración socialista permitió que esas reformas no se desdibujasen todavía más, y que en muchos casos fueran más allá — sobre todo en la obra de Largo Caballero en el Ministerio de Trabajo- de lo que los republicanos de izquierdas hubiesen deseado por ellos mismos en aquellas circunstancias. Esto es lo que explica, no ya la evolución del Partido Radical, que muy pronto se convirtió en refugio de intereses sociales conservadores, sino sobre todo de la disidencia derechista radical-socialista que hemos visto.

La postura de colaboración de los socialistas no era tan fácilmente criticable como se presenta a veces, pues la alternativa que se les presentaba era bien contemplar desde una oposición vigilante una reforma mucho más lenta y tímida (la que hubiera podido efectuar una concentración republicana), bien acelerarla, como hicieron participando en gobiernos republicanos-socialistas, ya que no era viable ni parlamentaria ni socialmente un gobierno socialista.

\section{LA ESTABILIDAD GUBERNAMENTAL EN LAS CORTES CONSTITUYENTES}

Tras haber analizado la función desempeñada por Acción Republicana en el sistema parlamentario de partidos, nos interesa ver el problema de la

(16) En este sentido se orientan las críticas dirigidas desde un punto de vista izquierdista frecuente en algunos historiadores y políticos en la actualidad; respecto a éstos cfr. por ejemplo las críticas comunistas respecto a la actuación socialista en la II República en El Pais, 19-7-77, «Tropezar en la misma piedra», Simón Sánchez Montero. 
estabilidad o inestabilidad gubernamental durante el primer bienio y hasta qué punto una u otra tuvieron relación con ese carácter de eje político del partido de Azaña. Lo primero que hay que establecer, por tanto, es si como se suele afirmar, el período republicano es una muestra paradigmática de debilidad e inestabilidad gubernamental.

El plazo de tiempo de las dos primeras legislaturas es demasiado breve como para sacar conclusiones respecto al sistema político plasmado en la Constitución; no cabe por ello más que observar el comportamiento Gobierno-Cortes de 1931 a 1936 sin pretender de hacer afirmaciones taxativas. Nos limitamos nosotros a estudiar la legislatura Constituyente para, con todas las reservas antedichas, intentar explicar la estabilidad gubernamental perceptible en el primer bienio.

Cuando se habla de la inestabilidad gubernamental en la República se afirma en general de toda ella sin distinguir entre las dos primeras legislaturas. Y al realizar un cómputo medio de la duración de cada gobierno, dado el elevado número de ellos que hubo en 1934-36, se obtiene una impresión falsa sobre el conjunto del período: en efecto, de 1931 a 1933 hubo una notable estabilidad gubernamental, muy superior en realidad a lo que puede indicar el hecho de que hubiera cinco gobiernos con una media de seis meses de duración cada uno de ellos (17). La primera crisis de octubre del 31 no impidió que el gobierno perdurase tan sólo con la pérdida de la participación de un partido minoritario, la Derecha Liberal Republicana. De más trascendencia, puesto que implicaba reducir la base del Gobierno a la izquierda del mismo al separarse el Partido Radical fue la de diciembre del mismo año, pero era una crisis obligada, puesto que venía tras la aprobación de la Constitución y subsiguiente elección de Presidente de la República.

Durante todo el período posterior de las Cortes Constituyentes se puede decir que hubo un único Gobierno, el de Azaña. Sin embargo, se produjo una crisis en junio del 33 , crisis de origen presidencial y que no significó variación alguna de importancia en la composición política del Gobierno, pues no se puede calificar de tal la incorporación a la mayoría de los escasísimos federales. No puede considerarse esta crisis como un incidente en las relaciones Gobierno-Cortes, puesto que el Gobierno Azaña no llegó a perder la confianza de las Cortes en ningún momento. El

(17) Computamos los siguientes Gobiernos: el de Alcalá Zamora, los tres de Azaña y el de Lerroux; no el de Martínez Barrio, puesto que su Presidente tenía en su poder el decreto de disolución, por lo que no cabían ya conflictos con las Cortes. Respecto al tiempo contamos los treinta meses que van desde abril del 31 a septiembre del 33; en octubre se produce ya la disolución de las Constituyentes. 
significado de la crisis había que estudiarlo al tratar de las relaciones Gobierno-Presidente de la República.

Igualmente sucedería con el tercer Gobierno Azaña, que políticamente hemos identificado al segundo, al acabar su vida tras la pérdida de la confianza presidencial; el Gabinete Lerroux que le sucedió ya no pudo gobernar con esas Cortes, siendo sustituido al recibir una votación de desconfianza por un Ministerio electoral, el de Martínez Barrio.

En términos de estabilidad real, de subsistencia de una misma mayoría y, lo que es decisivo, de un mismo programa de Gobierno, hay que considerar, por tanto, que desde octubre de 1931 a septiembre de 1933 el Gobierno fue único, con una política que, salvo en una mayor homogeneidad y decisión, tampoco se diferenciaba mucho de la desarrollada por el primer Gobierno provisional desde abril del 31 a octubre del mismo año.

Lo que nos interesa analizar ahora es cómo se produjo tal estabilidad de los Gobiernos de Azaña, en contraposición a la perpetua inestabilidad de los Gobiernos durante el segundo bienio. Pues si éstos caían en su mayor parte por disensiones interpartidistas, en cambio insistimos en que las crisis que hicieron caer a Azaña tuvieron un origen extraparlamentario y ajeno a las relaciones entre las partidos de la mayoría (18). ¿Qué factores concurrieron para que las relaciones Gobierno-Parlamento y las internas de la coalición no provocasen en la primera legislatura republicana las crisis que sí existieron en la segunda?

Es evidente que la estabilidad del primer bienio se produjo a pesar de la debilidad de los partidos. Si como ha escrito Blondel, la fortaleza y el arraigo de los partidos es la base de una posición firme de los gobiernos frente al Parlamento (19), es evidente que esta condición básica faltaba a las fuerzas políticas presentes en las Constituyentes -con la excepción socialista- Acción Republicana tenía el inconveniente fundamental de que era un pequeño partido, que si bien podía ofrecer un futuro prometedor en aquel momento, no tenía sino una escasa capacidad de iniciativa política. Los factores que enumeramos antes y que en alguna medida atenuaban este hecho podían mejorar su posición en el seno de la coalición gubernamental, pero en modo alguno podían llegar a compensarlo, ni siquiera esa función de partido eje ("pivot») de la coalición. Y no bastaba la disciplina de los socialistas para permitir al Gobierno dominar la Cáma-

(18) Varela, Partidos y Parlamento..., pág 49, incluye un cuadro con las crisis de gobierno habidas a lo largo de la República y sus causas.

(19) Vid. Introducción al estudio comparativo de los Gobiernos, pág. 434, Revista de Occidente, Madrid, 1972. 
ra, pues los restantes partidos republicanos gubernamentales eran, como sabemos, de pequeño tamaño o sin disciplina interna.

Desde esta perspectiva el papel de Acción Republicana queda más ajustado a sus propios términos. Ya que pese a que constituía un eficaz aglutinante de la coalición, no fue el elemento decisivo en último instante para evitar durante todo el primer bienio que los radical-socialistas dejasen de apoyar al Gobierno o que los socialistas hiciesen más caso a sus bases y a su ala izquierda que a sus responsabilidades gubernamentales.

Tanto frente a los riesgos por disensiones internas de la coalición, como frente a los que pudieran surgir por las injerencias de Alcalá Zamora en la política gubernamental (que sería precisamente por donde se iría a pique el Gobierno Azaña), el garante de la estabilidad de la mayoría no fue ni la hegemonía de ningún partido, ni la especial función de Acción Republicana, ni la solidaridad ideológica entre sus integrantes. Para explicar la estabilidad de los gobiernos de Azaña hay que recurrir a la personalidad de su presidente. Podrían, en efecto, buscarse los ejemplos necesarios de cómo cuando la coalición pasó por momentos difíciles (por cualquiera de los riesgos citados) fue la intervención personal de Azaña, por encima de su partido, actuando como Presidente del Gobierno, la que salvó la situalción.

De igual manera que Azaña representó un papel destacado como líder político en su partido, para el sistema de partidos y el sistema político republicano fue una figura en sí misma de gran trascendencia. El fenómeno de la personalización del poder como principal sustitutivo de la ausencia de organizaciones partidistas consolidadas ha sido afirmado por el autor antes citado (20). Personalización del poder que puede presentarse tanto como fenómeno positivo en épocas iniciales del desarrollo político de un país como en una fase tardía de las sociedades democráticas consolidadas (21).

Pues bien, en nuestra opinión fue la autoridad personal de Azaña sobre los partidos integrantes de la coalición, e incluso sobre los restantes partidos republicanos, lo que explica que pese a la debilidad del sistema de partidos y del suyo propio se mantuviera durante dos años sin perder la confianza del Parlamento (de los propios partidos de la mayoría, habría que precisar), a pesar de las difíciles circunstancias por las que atravesó.

Azaña fue adquiriendo con el transcurso de los meses en el primer

(20) Ibid. pág. 380.

(21) Sobre la personalización del poder en las sociedades modernas véase el interesante libro de Schwartzenberg, L'etat spectacle, págs. 16-118, Flammarion, 1977. 
bienio un carisma indiscutible. Primero fue tan sólo el prestigio consecuencia de su gestión como ministro de la Guerra, gestión que mereció el aplauso público en las Cortes de Ortega y Gasset, a pesar de la escasa simpatía mutua que ambos se profesaban. Tras su ascenso a la presidencia del Consejo de Ministros fue su capacidad para resolver los problemas parlamentarios, para ir sacando adelante leyes que parecían empresas casi perdidas, como en ciertos momentos pareció el Estatuto de Cataluña, sus brillantes intervenciones en las Cortes, etc., lo que le fue creando una aureola de líder político imbatible en las Cortes.

El aplastamiento de la revuelta de Sanjurjo y la inmediata aprobación de la Reforma Agraria y del Estatuto catalán señalan el punto más alto de su gestión como Presidente del Gobierno. De él se esperaba que resolviese cualquier problema, y a través de sus Memorias nos ha llegado cómo ante muchas dificultades los ministros correspondientes preferían que fuese él quien se enfrentase al Parlamento. La fama de imbatibilidad parlamentaria se debía en parte a su justificado prestigio de orador; en realidad, y Azaña era consciente de ello, pocos se atrevían a hacerle frente en las Cortes por temor a salir malparados.

Una atracción menos racional, más estrictamente carismática hacia la figura de Azaña vendría con posterioridad al primer bienio como consecuencia de la persecución y encarcelamiento de que fue objeto en octubre del 34. La figura del ex Presidente del Gobierno adquirió entonces un carácter de mito popular -así como de "monstruo" para las derechasdel que Azaña mismo se asustaba por lo que de él se esperaba. La base de esa atracción auténticamente carismática hay que encontrarla en este primer bienio, por la confianza que supo inspirar ante cualquier problema parlamentario o extraparlamentario con que se enfrentó la coalición republicano-socialista.

Este carisma, que llegaba en palabras de Prieto a auténtica adoración entre sus partidarios más acérrimos, estaba, como decimos, durante el primer bienio más ligado a elementos racionales; junto con la capacidad de superar las dificultades políticas hay que mencionar también el que Azaña se convirtió en el símbolo de una política determinada. Su actuación al frente del Gobierno le valió el personalizar ya para toda la República la política reformista de colaboración republicano-socialista. Sabemos que en la propia mente de Azaña estaba prevista tras la época de colaboración con los socialistas, una etapa de gobierno exclusivamente de los republicanos, para administrar las reformas realizadas; sin embargo, la ruptura de los republicanos adscritos a sendos bloques de derecha y de izquierda hizo 
imposible este proyecto. Azaña sería ya el hombre inevitable para un gobierno de izquierdas, que implicaba de una forma u otra la colaboración socialista.

Azaña llegó a encarnar así esta política, lo que le facilitaba el vencer las resistencias del Parlamento sobre cualquier tema. Su prestigio y su valor simbólico hacían que difícilmente se atreviesen los diputados -especialmente los más indisciplinados, los radical-socialistas- a hacerle frente en el Parlamento abiertamente, o incluso a arriesgarse a derribar al Gobierno. Azaña era insustituible y derrotarle podía implicar la disolución de Cortes.

Cabría pensar que la inasistencia a Cortes de los diputados de la mayoría durante el verano de 1933, que tanto mal hizo al Gabinete Azaña, hubiese sido menor de imaginar los diputados que iba a debilitar al Gobierno lo suficiente como para permitir al Presidente de la República cesar a Azaña tras las elecciones a vocales del Tribunal de Garantías. Porque con una mayoría que hubiese conservado el entusiasmo de hacía un año, difícilmente se hubiera atrevido Alcalá Zamora a cesar al Gobierno y luego a disolver las Cortes. Pero lo decisivo es que la propia mayoría había perdido la fe en el apoyo social con que contaba la política que realizaban (22).

Este personalismo que pese a su voluntad representó Azaña se manifestaba más allá del panorama parlamentario del sistema de partidos. En realidad era una personalización que ejercía su influencia en el conjunto del sistema político en su totalidad. La persona de Azaña era un eje que aglutinaba una serie de fuerzas políticas y sindicales en torno a una política. El simbolizaba esa política no sólo ante las minorías parlamentarias, sino ante las fuerzas sociales que respaldaban al Gobierno, aunque no fueran electores suyos. Esto se vería más tarde con toda claridad en los discursos «en campo abierto» de 1935, con las ingentes concentraciones de masas para estar presentes en sus actos públicos. No es que entonces Izquierda Republicana careciera de base de masas, pero en estas concentraciones es muy posible que el espectro político de los asistentes fuera bastante amplio. En menor grado esto era ya un fenómeno existente en el primer bienio, aunque como consecuencia de la propaganda anarcosindicalista sufriera la imagen de Azaña un cierto deterioro en 1933 entre los sectores más populares. Las gestiones que Azaña hizo en ocasiones con

(22) Las quejas de Azaña sobre este desinterés abundan en su diario, por ejemplo, Arrarás, Memorias intimas de Azaña, págs. 246 y 247, «Ediciones españolas», Madrid, 1939, referidas al 20 de julio y al 22 de agosto. No hay que despreciar tampoco el simple cansancio ante la inexistencia de vacaciones parlamentarias veraniegas como razón de la ausencia, Azaña, OC, IV, pág. 644. 
líderes de la UGT prueban el ascendiente que podía ejercer sobre las organizaciones de carácter sindical.

Todo esto tenía la consecuencia sobre el sistema de partidos, tal como se presentaba en el Parlamento, de que Azaña era, por sí mismo, el más fuerte elemento de cohesión de la mayoría. Por algo él afirmaba que la coalición podría estallar por disensiones extraparlamentarias (conflictos locales entre republicanos y socialistas por ejemplo), pero que en el Parlamento era indestructible (23). Elemento de cohesión de carácter subjetivo, por ese carácter simbólico de la nueva política republicana y por el carisma que llegó a adquirir.

Ha señalado Varela que «la talla de estadista de Azaña encontró dos limitaciones: la falta de apoyo de una sólida organización partidista y sus propios escrúpulos en personalizar el poder político» (24). Ya hablamos del primer punto. Respecto al segundo tiene razón Varela al afirmar la repulsión que a Azaña le producia la personalización del poder. Para él los motivos ideológicos y políticos, ventilados en el Parlamento como centro donde se plantean y resuelven los asuntos públicos, debían constituir lo fundamental de la política. Es cierto también que él no buscó su exaltación personal. Pero no se puede concluir que por todo ello esa personalización no se produjo.

Como hemos afirmado existió una indudable personificación de la política reformista en Azaña. Lo que sí es cierto es que Azaña no utilizó a fondo los recursos que esta situación le proporcionaba (25). El pudo desde haber intentado forzar la unión de los partidos republicanos antes de 1934, hasta haber fomentado su popularidad personal en el ejército mediante frecuentes visitas a los cuarteles (cuando lo hizo fue siempre un éxito), pasando por todos los recursos que el poder permite para fomentar una imagen pública. Azaña se negó a ir por este camino, esperando, por ejemplo, que la propia bondad de su reforma militar le acabaría granjeando la estima de los militares valiosos, o que su iniciativa de proponer la unión parlamentaria de los republicanos gubernamentales hecha en Santander a finales de 1932 bastaría para que dicha unión se produjese.

(23) Azaña, OC, IV, pág. 644.

(24) Partidos y Parlamento, pág. 91.

(25) Schwartzenberg distingue adecuadamente entre la personalización del poder, fenómeno que analizamos en qué medida se dio en Azaña, y el poder personal, esto es, la absorción por parte de una persona de todos los poderes. A pesar de las acusaciones de un sector de la prensa a Azaña de ser un "dictador» —en uno de los sistemas más parlamentaristas que ha conocido Europa...- durante 1932-33, y que llegaron a convertirse en una polémica pública, en ningún caso puede hablarse de poder personal en manos de Azaña, op. cit.. pág. 8. 
Naturalmente las cosas no eran tan sencillas ni tan racionales. Sin embargo, y pese a su inactividad en tal sentido, Azaña fue adquiriendo un valor personal difícilmente discutible, del que él era consciente, y que mostró toda su eficacia en 1936.

Para finalizar creemos que se pueden obtener dos conclusiones de este artículo.

Una relativa al papel que algunos partidos pequeños pueden desempeñar en un sistema de partidos, papel superior cualitativamente a su importancia numérica, que puede llegar incluso, si se dan ciertos factores de diversa naturaleza, a constituir el eje político sobre el que se apoya una coalición gubernamental. Esto no implica que la existencia de un partido de tales características garantice la estabilidad de la coalición en un sistema pluripartidista, sobre todo si, como en el caso republicano, es un sistema débil y no unidimensional. Sin embargo, constituye un factor importante para reforzar la cohesión de la coalición.

$Y$ en segundo lugar confirmar la eficacia de la personalización del poder como sustitutivo funcional de un partido fuerte que pueda garantizar la estabilidad de un gobierno de coalición, en circunstancias similares a las descritas. 